\title{
The effect of previous coronary artery stenting on short- and intermediate-term outcome after surgical revascularization in patients with diabetes mellitus
}

\author{
Henry A. Tran, MD, MSc, Scott D. Barnett, PhD, Sharon L. Hunt, MBA, Andrew Chon, MD, \\ and Niv Ad, MD
}

\begin{abstract}
Objectives: Percutaneous intervention for coronary revascularization is associated with an increased risk of repeat revascularization, especially in patients with diabetes mellitus. In this study we sought to examine the effect of previous percutaneous intervention on the rate of adverse perioperative outcome and intermediate-term survival in patients undergoing coronary artery bypass surgery.
\end{abstract}

\begin{abstract}
Methods: Between January 1, 2001, and December 31, 2006, 1758 consecutive patients with diabetes mellitus who underwent first-time isolated coronary artery bypass surgery were identified. Survival and major perioperative complications for 1537 patients who did not have prior percutaneous intervention (group 1) were compared with those in 221 patients with prior percutaneous intervention (group 2) after adjusting for baseline risk factors. Vital status was determined by using the National Death Index and Social Security Death Index. Age-adjusted survival at 2 years' follow-up was calculated with the Cox singular proportional hazards model.
\end{abstract}

Results: At baseline, group 2 patients had higher incidences of hypercholesterolemia and myocardial infarction. Compared with group 1 patient, group 2 patients had significantly higher operative mortality (adjusted odds ratio, 4.05; 95\% confidence interval, 1.41-11.63), perioperative major adverse cardiac events (adjusted odds ratio, 2.72; 95\% confidence interval, 1.08-6.85), and atrial fibrillation (adjusted odds ratio, 1.97; 95\% confidence interval, 1.29-3.01). Group 2 patients had worse age-adjusted survival at 2 years' follow-up (93.4\% vs $87.4 \%, P<.017)$.

Conclusions: Patients with diabetes mellitus and a history of percutaneous coronary stenting before coronary artery bypass surgery were found to have an increased risk of operative death, increased perioperative complications, and decreased age-adjusted survival at 2 years' follow-up.

Earn CME credits at

http://cme.ctsnetjournals.org

See related editorial on page 276 .

Multiple clinical trials and registries that compared the long-term outcome of coronary artery bypass grafting (CABG) and percutaneous coronary interventions (PCIs) have observed that patients initially treated with PCI have significantly higher rates of repeat revascularization procedures. ${ }^{1-7}$ The circumstances are even more precarious for diabetic patients because these patients have higher rates

From the Inova Heart and Vascular Institute, Falls Church, Va.

Received for publication Jan 5, 2009; revisions received Feb 20, 2009; accepted for publication March 8, 2009; available ahead of print May 13, 2009.

Address for reprints: Niv Ad, MD, Cheif, Cardiac Surgery, Inova Heart and Vascular Institute, 3300 Gallows Rd, Falls Church, VA 22042 (E-mail: niv.ad@inova.org). J Thorac Cardiovasc Surg 2009; 138:316-23

$0022-5223 / \$ 36.00$

Copyright (C) 2009 by The American Association for Thoracic Surgery doi:10.1016/j.jtcvs.2009.03.004 of progression of coronary artery disease, restenosis after PCI, and necessity for subsequent revascularization than nondiabetic patients. ${ }^{8,9}$ It is estimated that $13 \%$ to $26 \%$ of patients who initially underwent PCI will still undergo surgical revascularization within 10 years. ${ }^{10}$ In 2002 alone, PCI was performed in 652,000 patients, meaning that potentially between 65,000 and 170,000 of these patients might require $\mathrm{CABG}$ in the near future. ${ }^{11}$

Several recent studies have reported that a history of PCI before CABG is an independent predictor of in-hospital mortality and major adverse cardiac events (MACEs). In a cohort of patients with diabetes mellitus and triple-vessel disease undergoing elective $\mathrm{CABG}$, previous $\mathrm{PCI}$ was associated with nearly a 3-fold increased risk of in-hospital death and MACEs. ${ }^{12}$ Given the frequent use of stents and the common need for subsequent surgical revascularization, these findings might have significant implications for an increasing group of patients. However, conclusions from previous investigations have generally been limited to shortterm follow-up; intermediate-term and long-term outcomes after surgical intervention in such patients remain unclear.

The purpose of this study is to compare perioperative outcome and intermediate-term survival of patients with 


$$
\begin{aligned}
& \text { Abbreviations and Acronyms } \\
& \begin{aligned}
\text { CABG } & =\text { coronary artery bypass grafting } \\
\text { CI } & =\text { confidence interval } \\
\text { EF } & =\text { ejection fraction } \\
\text { MACE } & =\text { major adverse cardiac event } \\
\text { MI } & =\text { myocardial infarction } \\
\text { OE } & =\text { observed/expected } \\
\text { OR } & =\text { odds ratio } \\
\text { PCI } & =\text { percutaneous coronary intervention } \\
\text { STS } & =\text { Society of Thoracic Surgeons }
\end{aligned}
\end{aligned}
$$

diabetes mellitus who have a history of PCI before CABG with those in patients undergoing CABG without a history of PCI and similar Society of Thoracic Surgeons (STS)predicted risk of morbidity and mortality. In addition, we assessed whether intermediate-term survival was associated with the number of diseased vessels, left ejection fraction (EF), the number of stents, or the indication for CABG for patients with a history of PCI.

\section{MATERIALS AND METHODS \\ Patients and Setting}

The cohort for this study was composed of consecutive patients given diagnoses of a history of diabetes mellitus who underwent first-time isolated CABG at a single tertiary-care center between January 1, 2001, and December 31, 2006. Subjects were derived from a computerized database combining elements of the STS National Adult Cardiac Surgery Database (www.sts.org) and internal outcomes data collected for outcomes management. The STS database is the largest cardiac surgical database in the world and is comprised of information collected prospectively by independent monitors based on prespecified and standardized definitions regarding preoperative clinical characteristics, intraoperative variables, and perioperative complications.

This study was reviewed and approved by the Institutional Review Board of Inova Fairfax Hospital.

Patients were identified as having diabetes if they had a history of diabetes, regardless of the method of treatment. Patients with emergency or salvage operative status $(n=105)$, prior CABG $(n=83)$, or myocardial infarction (MI) within 24 hours of CABG $(n=77)$ were excluded from analysis. Patients were identified as having a history of PCI if they previously had a percutaneous procedure to unblock a narrowed coronary artery. We included only patients who had PCI with stents; patients with isolated percutaneous transluminal coronary angioplasty, unsuccessful percutaneous transluminal coronary angioplasty, or isolated atherectomy were excluded from analysis $(n=58)$.

Vital status was determined from the National Death Index and cross-referenced with the Social Security Death Index. The National Death Index is a database of death record information compiled from the 50 states, the District of Columbia, Puerto Rico, and the US Virgin Islands. The Social Security Death Index is slightly less sensitive but more specific than the National Death Index. Follow-up for mortality data was right censored on January 15 , 2008, and there was $100 \%$ follow-up.

\section{Clinical Definitions}

MACEs were defined as a composite end point of operative death, perioperative MI, postoperative intra-aortic balloon pumping, or postoperative cardiogenic shock. A perioperative MI within 24 hours was diagnosed based on the following criteria: creatine kinase MB value of greater than 5 times normal or new $\mathrm{Q}$ waves present in 2 or more contiguous electrocardiographic leads. A perioperative MI 24 hours after the operation was diagnosed based on either evolutionary ST-segment elevations, development of new Q-waves in 2 or more contiguous leads, new left bundle branch block, or increases in creatine kinase MB value of greater than 3 times normal.

Operative mortality included all deaths occurring during the hospitalization in which the operation was performed, even if after 30 days, and included those deaths occurring after discharge from the hospital but within 30 days of the procedure unless the cause of death was clearly unrelated to the operation. Death from any cause was defined as any death during followup. Death from cardiac causes was defined as death from any cardiac cause (eg, lethal arrhythmia, MI, or circulatory failure).

The STS-predicted risk of major morbidity/mortality is the estimated probability of a patient experiencing either operative mortality or one of the following 5 major perioperative complications: any reoperation, mediastinitis (deep sternal infection requiring operative intervention), renal failure (acute or worsening renal failure resulting in the increase of serum creatinine to $>2.0 \mathrm{mg} / \mathrm{dL}$, an increase of twice the baseline creatinine value, or new dialysis requirement), prolonged ventilation (pulmonary ventilation $>24$ hours), or permanent stroke (any neurologic deficit of abrupt onset not resolved within 24 hours).

\section{Perioperative Management}

Glucose control. All patients were initiated on the Portland Continuous Intravenous Insulin Protocol on the morning of surgical intervention, and this was continued until 72 hours postoperatively. Continuous insulin infusions were titrated to a serum glucose goal of less than $150 \mathrm{mg} / \mathrm{dL}$ by using a standardized protocol.

Myocardial preservation. All patients were managed with intermittent cold blood cardioplegic solution. The method of delivery was retrograde and antegrade, and reperfusion of the myocardium was accomplished with metabolically enhanced warm blood cardioplegic solution.

\section{Statistical Analysis}

Continuous data are presented as the mean \pm standard deviation. Categorical data are presented as the frequency and percentage. Between-group hypothesis tests were accomplished either by using the Student's $t$ test, the $\chi^{2}$ test, or unconditional logistic regression, where appropriate. Adjustment for potential confounding variables during logistic regression modeling was accomplished by using the individual patient-calculated modeled probability of mortality. ${ }^{13}$ Multivariate unconditional logistic regression modeling was performed to assess the relationship between operative mortality and 2-year mortality versus treatment group after adjustment for the potential confounding effects of preoperative clinical and demographic characteristics. Cox proportional hazard models were used to model the effect of select clinical parameters on 2-year survival, with statistical significance assessed by using the log-rank test. A further Cox model was used to adjust for the statistically significant age difference between the CABG and CABG plus PCI groups to estimate the effect of patient group on 2-year survival.

Observed/expected (OE) ratios of major perioperative complications (reoperation for bleeding, mediastinitis, renal failure, prolonged ventilation, permanent stroke, and operative morality) were calculated by dividing the observed number of events per stratum by the expected number of events. Expected numbers of events were derived from the summed stratum-specific probabilities of major perioperative complications based on preoperative clinical characteristics and comorbidities. Expected numbers of cases per strata were calculated by summing the modeled probabilities of achieving the target event. $P$ values were 2-tailed, with all analyses performed with SAS (version 9.1; SAS Institute, Inc, Cary, NC) and GraphPad Prism (version 4.03) software.

\section{RESULTS}

\section{Demographics}

A total of 1758 patients with diabetes mellitus who underwent $\mathrm{CABG}$ and met the inclusion criteria were identified 


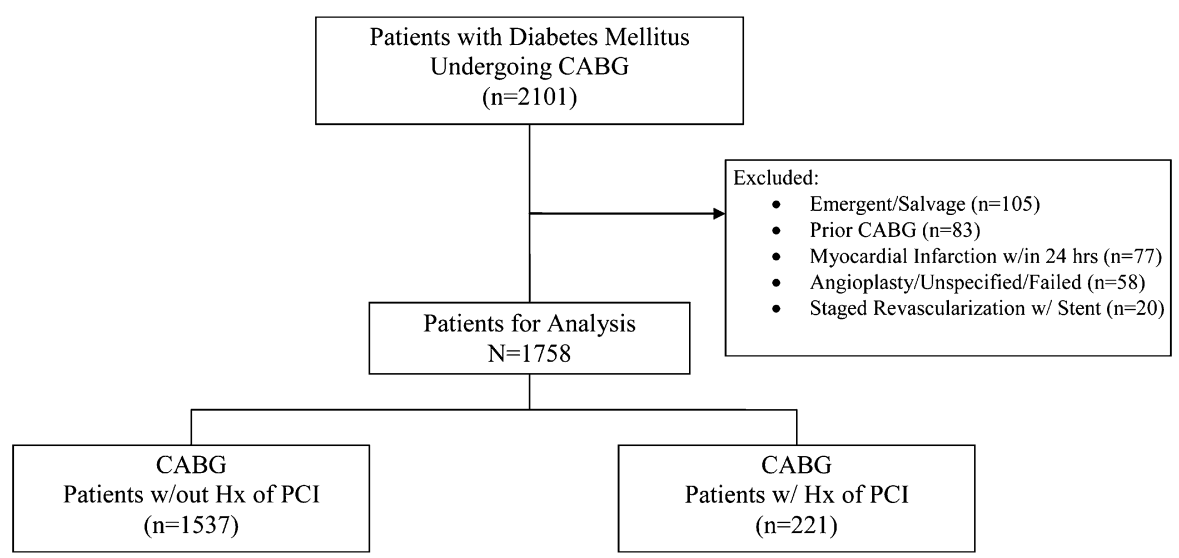

FIGURE 1. Participants. $C A B G$, Coronary artery bypass grafting; $H x$, history; $P C I$, percutaneous coronary intervention.

in the database (Figure 1). One thousand five hundred thirtyseven patients underwent CABG surgery without prior PCI, and 221 patients were identified as having a history of PCI with stenting before CABG. Of the 221 patients with prior PCI, $103(46.6 \%)$ patients had 1 stent and $118(53.4 \%)$ patients had multiple stents placed before surgical intervention.

Table 1 summarizes the perioperative characteristics of the patients. The average STS-modeled predicted risk of mortality or morbidity for patients undergoing CABG plus PCI was similar to that seen in patients undergoing CABG only $(2.2 \% \pm 2.2 \%$ and $1.9 \% \pm 2.2 \%$, respectively; $P<.113)$. In both groups the majority of patients were men older than 60 years; however, patients undergoing CABG plus PCI were younger than patients undergoing CABG only (60.1 vs 63.3 years, $P<.0001)$. Patients undergoing CABG plus PCI more frequently had a history of acute $\mathrm{MI}$ and hypercholesterolemia compared with patients undergoing $\mathrm{CABG}$ only. Although there was a difference in the incidence of history of acute MI, the average EF in both groups was similar. The distribution of diseased coronary vessels was significantly different; more patients in the CABG-only group had triple-vessel disease $(85.0 \%$ vs $73.8 \%, P<.001)$ and left main disease.

Patients undergoing CABG plus PCI were more often treated with insulin $(30.3 \%$ vs $23.6 \%)$ and less often treated with oral hypoglycemic medication $(57.5 \%$ vs $58.0 \%)$ or diet control (12.2\% vs $18.3 \%)$; however, these differences in treatments were not statistically significant $(P<.089)$.

Reflecting the higher incidence of $\mathrm{MI}$ and hypercholesterolemia, significantly more patients undergoing CABG plus PCI were treated with aspirin $(67.6 \%$ vs $60.7 \%, P<$ $.039), \beta$-blockers $(81.3 \%$ vs $74.4 \%, P<.021)$, and statins $(32.8 \%$ vs $27.4 \%, P<.001)$.

In the CABG plus PCI group, the mean time elapsed between the last PCI and CABG was $13.7 \pm 24$ months. In-stent restenosis was documented in $116(52.5 \%)$ patients by means of coronary angiographic analysis before CABG. The indication for $\mathrm{CABG}$ after PCI was determined if whether target vessel failure or progression of disease in the other vessels necessitated surgical revascularization. By using these criteria, there were 4 main indications for CABG: progression of de novo stenosis (135 [61.1\%] patients), restenosis of previous stents (44 [19.9\%] patients), combination of progression of disease and restenosis (37 [16.7\%] patients), or in-stent thrombosis (5 [2.3\%] patients).

\section{Perioperative Variables}

Both groups had similar crossclamp times, perfusion times, mean ventilation times, intraoperative blood transfusions, and hospital lengths of stay. There was no significant difference in the use of arterial grafts between the groups: $95.6 \%$ of patients undergoing CABG only and $95.0 \%$ of patients undergoing CABG plus PCI had at least 1 internal thoracic artery graft $(P<.63)$. The proportion of the CABG-only group who received more than 1 arterial graft (free radial artery or a second internal thoracic artery) during surgical intervention was similar to that in the CABG plus PCI group $(11.6 \%$ vs $11.8 \%, P<.911)$. Given that patients undergoing $\mathrm{CABG}$ only had more advanced multivessel disease, the average number of grafts in the CABG group was higher than in the CABG plus PCI group $(3.4 \pm 0.9$ vs $3.1 \pm$ $1.0, P<.001)$, but this difference is clinically irrelevant.

\section{Events}

Table 2 summarizes unadjusted and adjusted perioperative outcomes. The risk of operative mortality was significantly higher in the CABG plus PCI group (adjusted odds ratio [OR], 4.05; 95\% confidence interval [CI], $1.41-11.63)$. Of 21 operative deaths, $15(1.0 \%)$ occurred in the CABG-only group, and $6(2.7 \%)$ occurred in the CABG plus PCI group. Patients undergoing $\mathrm{CABG}$ plus PCI also had a significantly increased risk of perioperative MACEs (adjusted OR, 2.72; 95\% CI, 1.08-6.85). Patients undergoing CABG plus PCI more frequently had other perioperative complications, such as renal failure, new dialysis 
TABLE 1. Baseline patient characteristics

\begin{tabular}{|c|c|c|c|}
\hline & $\begin{array}{c}\text { CABG } \\
(n=1537) \\
\end{array}$ & $\begin{array}{c}\text { CABG + PCI } \\
(n=221)\end{array}$ & $P$ value \\
\hline \multicolumn{4}{|l|}{ Preoperative } \\
\hline Age (y) & $63.3 \pm 9.6$ & $59.7 \pm 9.7$ & .001 \\
\hline Male sex & $1137(74.0)$ & $167(75.6)$ & .614 \\
\hline BMI & $30.1 \pm 5.9$ & $31.2 \pm 6.3$ & .013 \\
\hline History of smoking & $778(50.6)$ & $120(54.3)$ & .306 \\
\hline Hypertension & $1188(77.3)$ & $181(81.9)$ & .123 \\
\hline History of stroke & $118(7.7)$ & $13(5.9)$ & .342 \\
\hline History of CHF & $247(16.1)$ & $34(15.4)$ & .794 \\
\hline Hypercholesterolemia & $1187(77.2)$ & $199(90.0)$ & .001 \\
\hline $\begin{array}{l}\text { Peripheral vascular } \\
\text { disease }\end{array}$ & $203(13.2)$ & $28(12.7)$ & .804 \\
\hline History of MI (>24 h) & $652(42.4)$ & $129(58.4)$ & .001 \\
\hline \multicolumn{4}{|l|}{ Diabetic treatment } \\
\hline Missing & $2(0.001)$ & 0 & - \\
\hline Insulin & $363(23.6)$ & $67(30.3)$ & - \\
\hline Oral & $892(58.0)$ & $127(57.5)$ & - \\
\hline Diet & $282(18.3)$ & $27(12.2)$ & .089 \\
\hline \multicolumn{4}{|l|}{ Medications } \\
\hline Aspirin & $933(60.7)$ & $149(67.4)$ & .055 \\
\hline ACE inhibitor & $581(38.8)$ & $84(38.0)$ & .952 \\
\hline$\beta$-Blocker & $1144(74.4)$ & $178(80.5)$ & .048 \\
\hline $\begin{array}{l}\text { Lipid-lowering, } \\
\text { nonstatin }\end{array}$ & $28(1.8)$ & $4(1.8)$ & .702 \\
\hline Lipid-lowering, statin & $421(27.4)$ & $74(33.5)$ & .001 \\
\hline $\begin{array}{l}\text { STS-predicted risk of } \\
\text { mortality }\end{array}$ & $2.2 \% \pm 2.2 \%$ & $1.9 \% \pm 2.2 \%$ & .113 \\
\hline $\begin{array}{l}\text { Predicted risk of } \\
\text { morbidity/mortality }\end{array}$ & $12.5 \% \pm 7.5 \%$ & $12.5 \% \pm 8.1 \%$ & .707 \\
\hline \multicolumn{4}{|l|}{ Ejection fraction } \\
\hline$<40 \%$ & $252(16.4)$ & $44(19.9)$ & - \\
\hline $41 \%-50 \%$ & $538(35.0)$ & $75(33.9)$ & - \\
\hline$>50 \%$ & 747 (48.6) & $102(46.2)$ & .423 \\
\hline \multicolumn{4}{|l|}{ No. of diseased vessels } \\
\hline 1 & $37(2.4)$ & $13(5.9)$ & - \\
\hline 2 & $191(12.0)$ & $45(20.4)$ & - \\
\hline 3 & $1307(85.0)$ & $163(73.8)$ & .001 \\
\hline Left main disease & 333 (21.7) & $38(17.2)$ & .127 \\
\hline $\begin{array}{l}\text { Time from last PCI to } \\
\text { CABG (mo) }\end{array}$ & - & $13.7 \pm 24.0$ & \\
\hline \multicolumn{4}{|l|}{ Intraoperative } \\
\hline $\begin{array}{l}\text { Aortic crossclamp time } \\
\quad(\min )\end{array}$ & $60.8 \pm 23.3$ & $59.5 \pm 23.7$ & .476 \\
\hline Perfusion time (min) & $90.4 \pm 29.2$ & $88.1 \pm 30.8$ & .289 \\
\hline$>1$ Arterial graft & $178(11.6)$ & $26(11.8)$ & .911 \\
\hline $\begin{array}{l}\text { No. of venous and arterial } \\
\text { grafts }\end{array}$ & $3.4 \pm 0.9$ & $3.1 \pm 1.0$ & .001 \\
\hline $\begin{array}{l}\text { Intraoperative PRBC } \\
\quad \text { (units) }\end{array}$ & $1.7 \pm 1.6$ & $1.3 \pm 0.8$ & .289 \\
\hline \multicolumn{4}{|l|}{ Postoperative } \\
\hline Hospital length of stay (d) & $7.5 \pm 10.8$ & $8.4 \pm 14.9$ & .309 \\
\hline Ventilation time (h) & $11.8 \pm 38.6$ & $15.2 \pm 66.5$ & .288 \\
\hline
\end{tabular}

Values are presented as the mean \pm standard deviation and number (percentage) as shown. $C A B G$, Coronary artery bypass grafting; $P C I$, percutaneous coronary intervention; $S D$, standard deviation; $B M I$, body mass index; $C H F$, congestive heart failure; $M I$, myocardial infarction; $A C E$, angiotensin-converting enzyme; STS, Society of Thoracic Surgeons; $P R B C$, packed red blood cell. requirement, prolonged ventilation, and reoperation, but only the incidence of atrial fibrillation reached statistical significance (adjusted OR, 1.97; 95\% CI, 1.29-3.01).

OE ratios of major perioperative complications were calculated by using expected incidences of complications from the national cohort of the STS database. Compared with the national cohort, patients undergoing $\mathrm{CABG}$ plus PCI experienced more complications than expected because the $\mathrm{OE}$ ratios exceeded 1 for all categories, except for mediastinitis. OE ratios for patients undergoing CABG plus PCI exceeded those of patients undergoing $\mathrm{CABG}$ only for all perioperative outcomes except permanent stroke (1.06 vs 1.37 ) and mediastinitis (0.56 vs 0.66$)$. The greatest disparity was a difference greater than 2-fold in the $\mathrm{OE}$ ratio among patients undergoing $\mathrm{CABG}$ plus $\mathrm{PCI}$ for operative mortality (1.22 vs 0.53$)$.

Major perioperative complications were also stratified according to the number of diseased vessels. Patients undergoing $\mathrm{CABG}$ only with double-vessel disease experienced significantly more strokes than patients undergoing CABG plus PCI with double-vessel disease $(3.1 \%$ vs $2.2 \%$, $P<.045)$. Furthermore, an analysis of perioperative complications segregated by the reason for CABG after PCI did not find any statistical differences.

Multivariable logistic regression revealed significant independent predictors of operative mortality as follows: age (OR, 1.11; 95\% CI, 1.05-1.18), crossclamp time (OR, $1.034 ; 95 \% \mathrm{CI}, 1.02-1.05)$, history of renal failure (OR, 5.44; 95\% CI, 1.54-19.23), and history of PCI (OR, 4.05; $95 \%$ CI, 1.41-11.63).

\section{Intermediate-Term Survival}

An age-adjusted hazard plot for all-cause mortality is shown in Figure 2. The median follow-up time was $3.6 \pm$ 2.0 years (CABG only, 3.6 years; CABG plus PCI, 3.4 years). At 2 years' follow-up, there were a total of 94 deaths: 78 deaths occurred in the CABG-only group, and 16 deaths occurred in the CABG plus PCI group. The age-adjusted survival of the CABG-only group was significantly better compared with that seen in the CABG plus PCI group $(93.4 \%$ vs $87.4 \%, P<.017)$.

Table 3 presents hazard ratios for all-cause mortality at 2 years' follow-up. Although low EF $(<40 \%)$ increased the risk of mortality for all patients, this was significant only in the CABG-only group (hazard ratio, 1.91; 95\% CI, 1.29-2.84). Hazard ratios for all-cause mortality at 2 years were not statistically different when analyzed by number of stents placed or number of diseased vessels.

Multivariable logistic regression for death at 2 years' follow-up identified the following variables as independent predictors of mortality: age (OR, 1.10; 95\% CI, 1.06-1.13), reduced $\mathrm{EF}(\mathrm{OR}, 1.03 ; 95 \% \mathrm{CI}, 1.01-1.05)$, peripheral vascular disease (OR, 3.30; 95\% CI, 1.97-5.54), and preoperative creatinine value (OR, $1.20 ; 95 \% \mathrm{CI}, 1.01-1.43)$. A history of 
TABLE 2. Frequency of perioperative complications by group

\begin{tabular}{lcccc}
\hline & CABG $(\mathbf{n}=\mathbf{1 5 3 7})$ & $\mathbf{C A B G}+\mathbf{P C I}(\mathbf{n}=\mathbf{2 2 1})$ & Unadjusted OR \pm 95\% $\mathbf{C I}$ & Adjusted OR \pm 95\% $\mathbf{C I}$ * \\
\hline MACEs & $19(1.2)$ & $8(3.6)$ & $2.47(1.09-5.60)$ & $2.72(1.08-6.85)$ \\
Permanent stroke & $25(1.6)$ & $3(1.4)$ & $0.83(0.25-2.78)$ & $1.212(0.35-4.18)$ \\
Transient stroke & $14(0.9)$ & $2(0.9)$ & $0.99(0.22-4.40)$ & $1.12(0.24-5.38)$ \\
Continuous coma & $5(0.3)$ & $0(0.0)$ & - & - \\
Prolonged ventilation time & $74(4.8)$ & $11(5.0)$ & $1.05(0.54-1.98)$ & $1.14(0.56-2.28)$ \\
Tamponade & $10(0.7)$ & $1(0.5)$ & $0.69(0.09-5.45)$ & $0.52(0.06-4.40)$ \\
Atrial fibrillation & $172(11.2)$ & $36(16.3)$ & $1.54(1.05-2.28)$ & $1.97(1.29-3.01)$ \\
Reoperation for bleeding & $22(1.4)$ & $3(1.4)$ & $0.95(0.28-3.19)$ & $0.98(0.29-3.34)$ \\
Renal failure & $57(3.7)$ & $9(4.1)$ & $1.10(0.53-2.26)$ & $1.06(0.49-2.30)$ \\
Renal failure/dialysis required & $17(1.1)$ & $5(2.3)$ & $2.07(0.76-5.68)$ & $1.80(0.57-5.70)$ \\
Operative death & $15(1.0)$ & $6(2.7)$ & $2.65(1.03-6.85)$ & $4.05(1.41-11.63)$ \\
\hline
\end{tabular}

*Adjusted for age, sex, body mass index, hypertension, smoking, congestive heart failure, left ventricular ejection fraction, New York Heart Association functional class, family history of coronary artery disease, preoperative platelet use, arrhythmia, cerebrovascular accident, peripheral vascular disease, chronic obstructive pulmonary disease, history of renal failure, and crossclamp time. $C A B G$, Coronary artery bypass grafting; $P C I$, percutaneous coronary intervention; $O R$, odds ratio; $C I$, confidence interval.

PCI (OR, 1.76; 95\% CI, 0.92-3.39) predicted mortality but with a CI that suggested no statistical significance.

\section{DISCUSSION}

We observed that diabetic patients with a history of PCI with stenting before $\mathrm{CABG}$ had a significantly higher adjusted risk of operative mortality and worse age-adjusted survival at 2 years' follow-up compared with that seen in similar patients without a history of PCI. The operative mortality for the CABG-only group was low $(1.0 \%)$ and similar to mortality rates reported by other clinical registries, such as the New York State, Northern New England, and Texas State databases. ${ }^{4,6,14}$ We also found that the risk of MACEs was significantly increased in patients undergoing CABG plus PCI.

To our knowledge, this is the first observational study to report on the effect of a history of prior PCI on both early and intermediate-term outcomes in diabetic patients undergoing subsequent CABG. Although an EF of less than $40 \%$ was associated with worsened survival in the CABG-only group, we did not observe that preoperative factors, such as the number of stents, left main disease, indication for sur-

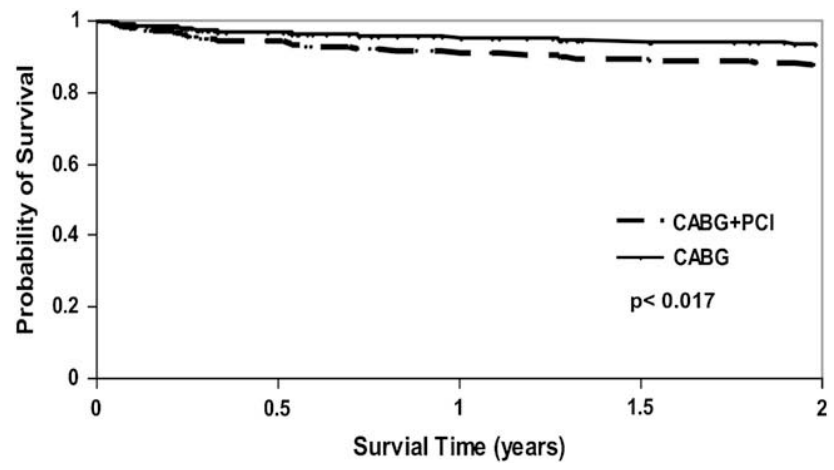

FIGURE 2. Hazard plot adjusted for age: comparison between patients undergoing coronary artery bypass grafting $(C A B G)$ only and patients undergoing coronary artery bypass grafting plus percutaneous coronary intervention $(P C I)$.

gical intervention after PCI, or severity of coronary disease, were prognostic of intermediate-term outcome. However, multivariate analysis demonstrated that age, reduced $\mathrm{EF}$, peripheral vascular disease, and increased preoperative creatinine value independently predicted death at 2 years' follow-up. A history of prior PCI was also recognized as a predictor of death at 2 years' follow-up, but the CIs did not achieve statistical significance and might be related to lack of power.

Possibly because of the clinical equipoise regarding the survival benefits of CABG compared with PCI, considerable practice variation exists in determining which strategy to initially use for revascularization. Data from multiple clinical registries have reported superior survival and decreased need for repeat revascularization with $\mathrm{CABG}$ compared with PCI in patients with multivessel disease. ${ }^{4-6}$ However, some results from randomized trials in the stent era have

TABLE 3. Hazard ratios of all-cause mortality at 2 years' follow-up

\begin{tabular}{|c|c|c|c|}
\hline & $\begin{array}{l}\text { All patients } \\
(\mathrm{n}=1758)\end{array}$ & $\begin{array}{c}\text { CABG } \\
(n=1537)\end{array}$ & $\begin{array}{c}\text { CABG }+ \text { PCI } \\
(\mathbf{n}=\mathbf{2 2 1})\end{array}$ \\
\hline $\mathrm{CABG}+\mathrm{PCI}$ & $1.49(0.86-2.61)$ & - & - \\
\hline $\mathrm{EF}(\%)$ & $0.97(0.96-0.99)$ & $0.97(0.95-0.99)$ & $0.98(0.94-1.02)$ \\
\hline $\mathrm{EF}<40 \%$ & $2.49(0.47-4.21)$ & $2.77(1.57-4.88)$ & $1.31(0.31-5.46)$ \\
\hline $\mathrm{EF} 41 \%$ to $50 \%$ & $1.43(0.87-2.37)$ & $1.34(0.77-2.35)$ & $1.82(0.57-5.72)$ \\
\hline $\mathrm{EF}>50 \%$ & - & - & - \\
\hline Left main disease & $1.06(0.64-1.76)$ & $1.05(0.60-1.82)$ & $1.24(0.35-4.40)$ \\
\hline $\begin{array}{c}\text { Triple-vessel } \\
\text { disease }\end{array}$ & $0.52(0.21-1.29)$ & $0.45(0.17-1.25)$ & $1.02(0.13-7.86)$ \\
\hline $\begin{array}{l}\text { Double-vessel } \\
\text { disease }\end{array}$ & $0.44(0.15-1.30)$ & $0.40(0.12-1.34)$ & $0.60(0.06-6.65)$ \\
\hline $\begin{array}{l}\text { Single-vessel } \\
\text { disease }\end{array}$ & - & - & - \\
\hline \multicolumn{4}{|l|}{$\begin{array}{c}\text { No. of stents } \\
\text { placed }\end{array}$} \\
\hline$>1$ vs 1 & - & - & $0.43(0.15-1.25)$ \\
\hline$>2$ vs $\leq 2$ & - & - & $0.26(0.03-1.97)$ \\
\hline
\end{tabular}


been discordant. ${ }^{1,2}$ The Bypass Angioplasty Revascularization Investigation trial observed a significant survival advantage with CABG over angioplasty in diabetic patients, whereas the Arterial Revascularization Therapies Study trial found no difference between surgical intervention and stenting. ${ }^{3,15}$ Regardless, data from trial and registry data have consistently shown that nondiabetic and diabetic patients treated with primary CABG have decreased necessity for reintervention compared with patients treated with PCI.

The necessity of repeat revascularization is magnified in diabetic patients because they have more adverse outcomes after PCI. Although procedural success with PCI in diabetic patients is equivalent to that seen in nondiabetic patients, the rate of symptom recurrence and restenosis after stent deployment is significantly increased in diabetic patients. ${ }^{16,17}$ Drug-eluting stents significantly reduce restenosis; however, even recent registry data have continued to report improved outcomes with CABG over drug-eluting stents in terms of lower mortality, MI, and repeat revascularization. ${ }^{18,19}$ Thus despite the attempts to defer CABG by pursuing stenting initially in patients with multivessel disease, CABG is merely delayed at substantial expense and higher cumulative procedural morbidity, mortality, or both.

Our findings are consistent with other reports in the literature that have been previously focused on in-hospital outcomes. Thielmann and colleagues ${ }^{20}$ examined patients undergoing first-time elective CABG and concluded that a history of prior PCI was an independent risk factor for significantly increased in-hospital mortality and MACEs. This conclusion was recently confirmed in a large multicenter study. ${ }^{21}$ In a subset of diabetic patients with triple-vessel disease, these authors found a similarly increased risk of in-hospital mortality. ${ }^{12}$ In a large cohort of 6032 patients, Hassan and associates ${ }^{22}$ observed that patients with prior PCI had greater in-hospital morality after CABG, despite having less coronary disease and comorbidities. One microsimulation study, using previously published data, estimated that prior coronary stenting worsened 10-year survival of patients undergoing $\mathrm{CABG}$ by $3.3 \% .^{23} \mathrm{~A}$ reanalysis of data from the Ischemia Management with Accupril Post Bypass Graft via Inhibition of the Converting Enzyme study demonstrated that patients with prior PCI had worse outcome after $\mathrm{CABG}$, as manifested by increased hospitalization for unstable angina and need for coronary revascularization. ${ }^{24}$

These previous studies could not completely elucidate why patients with previous PCI carry an increased operative risk, and unfortunately, our study is similarly limited in that respect. However, there are several mechanisms worthwhile of consideration that might help to explain the cause behind this increased risk. Patients who require a repeat revascularization procedure with CABG after PCI might have a more progressive form of atherosclerosis, perhaps promoting more numerous coronary lesions or a higher rate of restenosis. In this study patients undergoing CABG plus PCI had a higher incidence of hypercholesterolemia and MI; the majority of these patients underwent surgical intervention because of progression of de novo coronary artery disease presumably refractory to appropriate medical management after stenting.

Prior PCI might not only be a proxy marker of more advanced or aggressive disease, but the presence of a stent might itself induce deleterious mechanisms inside the coronary artery. Stenting can inhibit protective collateralization, resulting in more acute presentation of disease. It has been shown to induce periprocedural myocardial injury, which initiates a secondary inflammatory cascade, formation of platelet microaggregates, and microvascular plugging from plaque debris and microemboli. ${ }^{25,26}$ The presence of a previous stent might force graft anastomoses to be inserted more distally into target vessels with smaller diameters, thereby compromising runoff and patency rates. Moreover, there is emerging evidence that the use of newer drug-eluting stents, especially in off-label situations, might reduce restenosis at the high cost of late in-stent thrombosis with associated high mortality. ${ }^{27}$ This risk has been found to be higher in diabetic patients and persists with time. ${ }^{28}$ These patients might be especially vulnerable to in-stent thrombosis while not taking antiplatelet agents, such as during the perioperative period. ${ }^{29}$

The burgeoning recognition in the literature of the effects of prior PCI on CABG outcomes has yet to translate into changes of clinical practice and management. Current risk models to assess the risk of operative mortality and morbidity after $\mathrm{CABG}$ do not adequately prognosticate the additional risk conferred by a history of prior PCI. For instance, neither the logistic or additive EuroSCORE calculators include a history of prior PCI as a risk factor. Although the STS CABG risk model does use a history of prior PCI as a risk factor, it is only weighted in risk calculations if PCI occurred within 6 hours of CABG. Perhaps what might be required is to re-examine the cohorts from which these models are derived to accurately determine the magnitude of the increased risk of prior PCI. In the interim, patients who present for CABG after previous PCI should at the very least be followed with increased attention and surveillance to mitigate perioperative and long-term complications.

\section{Limitations}

Several limitations exist with this study. This was a nonrandomized retrospective study at a single center, which might limit the ability to generalize these results to other institutions. However, a strength of this study is that the data were gathered prospectively by using standardized definitions, which minimizes selection and recall bias. Although the 2 groups in this study were not randomized, the STS-predicted risk of mortality was similar for both groups in this study, which suggests the differences in baseline risk factors were minimally significant. We could not control for differences in management preoperatively or 
after discharge, such as statin use. Despite a high prevalence of hypercholesterolemia, only a minority of patients in both groups were treated with statins at the time of surgical intervention, and significantly more patients in the CABG plus PCI group received statins. Several contemporary studies observed similarly low rates of statin therapy $(35.9 \%$ to $46 \%$ ) in patients with coronary artery disease and CABG. ${ }^{30,31}$ It is likely that more prevalent preoperative statin use, especially in the CABG plus PCI group, could have led to reduced need for surgical revascularization and perioperative MACEs. ${ }^{32}$

Because of limited cardiac catheterization data, the type of stent (bare metal or drug eluting) was unable to be ascertained in many cases. Therefore we could not comment on whether there were any associated differences in outcome based on the type of stent used. In approximately $4 \%$ of patients, the location of previous stents was unknown as well; thus in some instances it was unknown whether a bypass graft was placed in a stented vessel.

Lastly, clinical data on patients after discharge were limited and inconsistent. We were unable to quantify the need for repeat revascularization or the incidence of graft failure. Although we were able to obtain mortality data after discharge, for approximately $30 \%$ of the patients in each group, the cause of death was not reported. Thus we could not specifically relate the difference in survival between the groups to cardiac or noncardiac factors.

\section{CONCLUSION}

The findings of this study highlight the significantly increased perioperative and intermediate-term risk of diabetic patients who had PCI before CABG. With improved decision making and patient selection, hopefully clinical outcomes will improve by selecting the most appropriate method of initial revascularization to reduce the need for patients to have repeat revascularizations. This might best be accomplished by a multidisciplinary team involving at least a cardiologist and cardiac surgeon, who cooperatively can analyze and discuss not only the immediate risks and benefits of revascularization but also the future hazards should a repeat procedure be required.

\section{References}

1. Coronary artery bypass surgery versus percutaneous coronary intervention with stent implantation in patients with multivessel coronary artery disease (the Stent or Surgery trial): a randomized controlled trial. Lancet. 2002;360:965-70.

2. Rodriquez AE, Baldi J, Fernandez-Pereira CF, Navia J, Rodriguez-Alemparte M, Delacasa A, et al. Five-year follow-up of the Argentine randomized trial of coronary angioplasty with stenting versus coronary bypass surgery in patients with multiple vessel disease (ERACI II). J Am Coll Cardiol. 2005;46:582-8.

3. Serruys PW, Ong ATL, van Herwerden LA, Sousa JE, Jatene A, Bonnier JJ, et al. Five-year outcomes after coronary stenting versus bypass surgery for the treatment of multivessel disease: the final analysis of the Arterial Revascularization Therapies Study (ARTS) randomized trial. J Am Coll Cardiol. 2005;46:575-81.

4. Hannan EL, Racz MJ, Walford G, Jones RH, Ryan TJ, Bennett E, et al. Long-term outcomes of coronary-artery bypass grafting verses stent implantation. $N$ Engl J Med. 2005;352:2174-83.
5. Niles NW, McGrath PD, Malenka D, Quinton H, Wennberg D, Shubrooks SJ, et al. Survival of patients with diabetes and multivessel coronary artery disease after surgical or percutaneous coronary revascularization: results of a large regional prospective study. Northern New England Cardiovascular Disease Study Group. J Am Coll Cardiol. 2001;37:1008-15.

6. Kohsaka S, Goto M, Virani S, Lee VV, Aoki N, Elayda MA, et al. Long-term clinical outcome of coronary artery stenting or coronary artery bypass grafting in patients with multiple-vessel disease. J Thorac Cardiovasc Surg. 2008;16:500-6.

7. Booth J, Clayton T, Pepper J, Nugara F, Flather M, Sigwart U, et al. Randomized, controlled trial of coronary artery bypass surgery versus percutaneous intervention in patients with multivessel coronary artery disease: six-year follow-up from the Stent or Surgery Trial (SoS). Circulation. 2008;118:381-8.

8. Mehran R, Dangas GD, Kobayashi Y, Lansky AJ, Mintz GS, Aymong ED, et al. Short- and long-term results after multivessel stenting in diabetic patients. $J$ Am Coll Cardiol. 2003;43:1328-54.

9. Schofer J, Schlüter M, Rau T, Hammer F, Haag N, Mathey DG. Influence of treatment modality on angiographic outcome after coronary stenting in diabetic patients: a controlled study. J Am Coll Cardiol. 2000;35:1554-9.

10. Hoffman SN, TenBrook JA, Wolf MP, Pauker SG, Salem DN, Wong JB. A metaanalysis of randomized controlled trials comparing coronary artery bypass grafting with percutaneous transluminal coronary angioplasty: one to eight-year outcomes. J Am Coll Cardiol. 2003;41:1293-304.

11. Thom T, Haase N, Rosamond W, Howard VJ, Rumsfeld J, Manolio T, et al. Heart disease and stroke statistics-2006 update: a report from the American Heart Association Statistics Committee and Stroke Statistics Subcommittee. Circulation. 2006;113:e85-151.

12. Thielmann M, Neuhauser M, Knipp S, Kottenberg-Assenmacher E, Marr A, Pizanis N, et al. Prognostic impact of previous percutaneous coronary intervention in patients with diabetes mellitus and triple-vessel disease undergoing coronary artery bypass surgery. J Thorac Cardiovasc Surg. 2007;134:470-6.

13. Shroyer AL, Cooms LP, Peterson ED, Eiken MC, DeLong ER, Chen A, et al. The Society of Thoracic Surgeons: 30-day operative mortality and morbidity risk models. Ann Thorac Surg. 2003;75:1856-65.

14. Malenka DJ, Leavitt BJ, Hearne MJ, Robb JF, Baribeau YR, Ryan TJ, et al. Comparing long-term survival of patients with multivessel coronary disease after CABG or PCI: analysis of BARI-like patients in northern New England. Circulation. 2005;112(suppl):1371-6.

15. Bypass Angioplasty Revascularization Investigation (BARI) Investigators. Comparison of coronary bypass surgery with angioplasty in patients with multivessel disease. N Engl J Med. 1996;335:217-25.

16. Van Belle E, Bauters C, Hubert E, Bodart JC, Abolmaali K, Meurice T, et al. Restenosis rates in diabetic patients: a comparison of coronary stenting and balloon angioplasty in native coronary vessels. Circulation. 1997;96:1454-60.

17. Kornowski R, Mintz GS, Kent KM, Pichard AD, Satler LF, Bucher TA, et al. Increased restenosis in diabetes mellitus after coronary interventions is due to exaggerated intimal hyperplasia: a serial intravascular ultrasound study. Circulation. 1997;95:1366-9.

18. Hannan EL, Wu C, Walford G, Culliford AT, Gold JP, Smith CR, et al. Drug-eluting stents vs. coronary-artery bypass grafting in multivessel coronary disease. N Engl J Med. 2008;358:331-41.

19. Javaid A, Steinberg D, Buch AN, Corso PJ, Boyce SW, Pinto TL, et al. Outcomes of coronary artery bypass grafting versus percutaneous coronary intervention with drug-eluting stents for patients with multivessel coronary artery disease. Circulation. 2007; 116:I200-6.

20. Thielmann M, Leyh R, Massoudy P, Neuhäuser M, Aleksic I, Kamler M, et al. Prognostic significance of multiple previous percutaneous coronary interventions in patients undergoing elective coronary artery bypass surgery. Circulation. 2006; 114(suppl I):1441-7.

21. Massoudy P, Thielmann M, Lehmann N, Marr A, Kleikamp G, Maleszka A, et al. Impact of prior percutaneous coronary intervention on the outcome of coronary artery bypass surgery: a multicenter analysis. J Thorac Cardiovasc Surg. 2009; 137:840-5.

22. Hassan A, Buth KJ, Baskett RJ, Ali IS, Maitland A, Sullivan JA, et al. The association between prior percutaneous coronary intervention and short-term outcomes after coronary artery bypass grafting. Am Heart J. 2005;150:1026-30.

23. Rao C, Stanbridge RDL, Chikwe J, Pepper J, Skapinakis P, Aziz O, et al. Does previous percutaneous coronary stenting compromise the long-term efficacy of subsequent coronary artery bypass surgery? A Microsimulation Study. Ann Thorac Surg. 2008;85:501-7.

24. Chocron S, Baillot R, Rouleau JL, Warnica WJ, Block P, Johnstone D, et al. Impact of previous percutaneous transluminal coronary angioplasty and/or 
stenting revascularization on outcomes after surgical revascularization: insights from the imagine study. Eur Heart J. 2008;29:673-9.

25. Toutouzas K, Colombo A, Steanadis C. Inflammation and restenosis after percutaneous coronary interventions. Eur Heart J. 2004;25:1679-87.

26. Herrmann J. Peri-procedural myocardial injury: 2005 update. Eur Heart J. 2005; 26:2493-519.

27. Pfisterer M, Brunner-La Rocca HP, Buser PT, Rickenbacher P, Hunziker P, Mueller C, et al. Late clinical events after clopidogrel discontinuation may limit the benefit of drug-eluting stents: an observational study of drug-eluting versus bare-metal stents. J Am Coll Cardiol. 2006; 48:2584-91.

28. Serruys P, Daemen J. Are drug-eluting stents associated with a higher rate of late thrombosis than bare metal stents? Circulation. 2007;115:1433-9.
29. Ong AT, McFadden EP, Regar E, de Jaegere PP, van Domburg RT, Serruys PW. Late angiographic stent thrombosis (LAST) events with drug-eluting stents. J Am Coll Cardiol. 2005;35:2088-92.

30. Kulik A, Levin R, Ruel M, Mesana TG, Solomon DH, Choudhry NK. Patterns and predictors of statin use after coronary artery bypass graft surgery. J Thorac Cardiovasc Surg. 2007;134:932-8.

31. Liakopoulos OJ, Choi YH, Haldenwang PL, Strauch J, Wittwer T, Dorge H, et al. Impact of perioperative statin therapy on adverse postoperative outcomes in patients undergoing cardiac surgery: a meta-analysis of over 30000 patients. Eur Heart J. 2008;29:1548-59.

32. Pan W, Pintar T, Anton J, Lee V, Vaughn WK, Collarg CD. Statins are associated with a reduced incidence of perioperative mortality after coronary artery bypass graft surgery. Circulation. 2004;110:II45-9. 